\title{
A New Graduate Course on Modular Construction: University of Nevada, Las Vegas
}

\author{
Jin Ouk $\mathrm{CHOI}^{1 *}$ \\ ${ }^{1}$ Assistant Professor, Department of Civil and Environmental Engineering and Construction, \\ University of Nevada, Las Vegas \\ *Corresponding author's e-mail: jinouk.choi@unlv.edu
}

\begin{abstract}
Modular construction has been highlighted as one of the key technologies which can significantly improve the construction industry by major professional conferences (i.e., 2017 CII (Construction Industry Institute) Annual Conference, Autodesk University (Las Vegas 2017), CONEXPCON/AGG) held in 2017. It is now evident that practitioners in the construction industry recognize and pay more attention to the value of modular construction, and consider implementing it. One of the enablers that can accelerate higher levels of modularization across the industry is changing project stakeholders' stick-build paradigm to modularization. However, as most of the engineering schools in the U.S. teach courses based on the stick-build approach, students do not have an opportunity to learn the modular approach. Due to this reason, when they become owners, designer, and contractors, they are captured by the stick-build paradigm and more likely become reluctant to expand their modularization "comfort zones." To accelerate higher levels of modularization and meet the need of students and the industry, the Department of Civil and Environmental Engineering and Construction at the University of Nevada, Las Vegas, led by Dr. Jin Ouk Choi, recently created a new graduate-level course on Modular Construction in 2017 which covers an overall understanding of modular construction concepts including, advantages, disadvantages, impediments, industry status, business case process, execution plans, critical success factors, and standardization strategies of modularization. This paper will introduce the course in terms of its vision, learning objectives, development procedure, structure, contents, and students' feedback who took the course in Spring 2017.
\end{abstract}

\section{KEYWORDS}

Teaching Offsite and Modular Construction; Graduate Course; Changing Stick-build Paradigm to Modularization; Education

\section{INTRODUCTION}

To accelerate higher levels of modularization and meet the need of students and the industry, the Department of Civil and Environmental Engineering and Construction at the University of Nevada, Las Vegas, led by the author, recently created a new graduate-level course on Modular Construction in 2017 which covers an overall understanding of modular construction concepts including, advantages, disadvantages, impediments, industry status, business case process, 
execution plans, critical success factors, and standardization strategies of modularization. The author was hired as a tenure-track Assistant Professor (Rank 2) in the area of Construction Engineering Management (CEM) in the Department of Civil and Environmental Engineering and Construction (CEEC) of the Howard R. Hugest College of Engineering at the University of Nevada, Las Vegas (UNLV) as of August 1, 2016. Before 2017, there was no undergraduate or graduate course that covers the topic related to prefabrication, preassembly, modularization, or off-site construction. Thus, the author developed the course and created a syllabus, all the teaching slides, assignments, exams, and term projects from scratch.

In Fall 2016, the author got approval to create a graduate course (3 credit hours), as a special topic, CEE/CEM "Advanced Special Topics in Construction Management/Civil Engineering: Modular Construction" for Spring 2017. The lecture was delivered twice a week, an hour and fifteen minutes per lecture, from January 17 to May 11,2017. Since then, the author and the faculty in the Department of Civil and Environmental Engineering and Construction (CEEC) of the Howard R. Hughes College of Engineering at UNLV moved forward in creating a regular graduate course. In Summer and Fall 2017, 1) the author submitted a new graduate course proposal, 2) the Graduate College completed technical review of the new course proposal, 3) the Department of CEEC and the College of Engineering curriculum committee approved the course, 4) the Graduate Course Review Committee reviewed and approved the course. From Spring 2018, the course will be delivered every year in Spring.

One of the author's long-term career goal, including research and teaching, is creating an optimum environment for broader and more effective use of modularization. To achieve this goal the author has been active in terms of research. To summarize key research activities, the author: (1) examined links between modularization critical success factors and project performance (Choi 2014); (2) investigated the standardization strategies for modular construction (O'Connor et al. 2015a); (3) identified differences in the planning and execution of modular projects (O'Connor et al. 2015b); and (4) presented a new modularization business case process for determining the degree to which modularization will be implemented (O'Brien et al. 2015).

According to the finding of one of the author's research (O'Connor et al. 2017), one of the enablers that can accelerate higher levels of modularization across the industry is changing project stakeholders' stick-build paradigm to modularization. However, as most of the engineering schools in the U.S. teach courses based on the stick-build approach, students do not have an opportunity to learn the modular approach. Higher education institutions should teach the modular approach, not just stick-build approach (O'Connor et al. 2017). There are some universities initiated teaching it, but they are just a few. More engineering colleges should promote and teach modular approach.

\section{A NEW GRADUATE COURSE ON MODULAR CONSTRUCTION}

Aligned with the author's long-term career goal, the author created the course to accelerate higher levels of modularization and meet the need of students and the industry based on the author's extensive research experience on modularization. The author invested extensive and comprehensive effort to develop the course that covers a broad range of topics on modularization for graduate students. The detailed information on the course is followed. 


\section{Course catalog description}

The course catalog description was prepared to describe the course concisely. The description is as follow: "This course will give students an overall understanding of modular construction (modularization) concepts including, advantages, disadvantages, impediments, industry status, business case process, execution plan, critical success factors, and standardization strategy of modularization."

\section{Course requirements}

There was no prerequisite course to attract more graduate students in the College of Engineering. However, graduate standing was required, or instructor's consent was needed to be enrolled. Also, students were required to have an understanding of conventional stick-built construction method, practices, and management. Some may argue that the understanding of stick-built approach is not required to learn a new design process - modular approach. However, the author decided to have this requirement to deliver the course more effectively and efficiently to graduate students. If not, quality or knowledge depth of the course may be sacrificed. In addition to the graduate standing requirement, the students were asked to engage in the following activities:

- Attend class

- Read assigned material before class sessions

- Participate in class discussions

- Complete two project assignments (report and presentation)

- Complete a term project - synthesis report

- Complete an examination

\section{Course format}

The course was developed in a lecture format. Class lectures were premised on familiarity with assigned readings. Students were expected to participate in reading groups throughout the semester. The reading assignments were passed out each week, and the reading materials (journal articles or reports) was posted on Blackboard in advance. The students were responsible for all reading assignments and class handouts whether or not covered in class or listed on the syllabus. In the syllabus and at the first class, the instructor recommended the students to bring their copy of reading materials to each lecture (used as a reference). Also, PPT slides were available on Blackboard and students were expected to have their copy of PPT slides with them in class.

\section{Course topics}

The following topics were covered in the course. By importance and maturity of the topic, the author divided the topics into two categories: core or advanced.

Core topics:

- Introduction of Modular Construction

- Advantage \& Disadvantage of Modular Construction

- Industry Status on Modular Construction

- Module

- Opportunities and Challenges of Modular Methods in Dense Urban Environment

- Module Transportation

- CII Strategic Decision Tool for PPMOF

- Business Case Process and Analysis for Modularization 
- Execution Plan Differences

- Critical Success Factors and Enablers

- Links between Modularization Critical Success Factors and Project Performance

- Standardization Strategy for Industrial Modularization

- Industry-Wide Maximization Enablers for Higher Levels of Modularization

Advanced topics:

- Automation in Modular Construction

- Modular Building

- Standard Plant Design

- Accelerated Bridge Construction (Guest Lecture)

- Learnings from Shipbuilding Industry

- UNLV Solar Decathlon Project: Lessons Learned (Guest Lecture)

Per this classification, the exam questions only covered the contents covered in the core topics.

\section{Learning outcomes}

The course's learning outcomes are as follow:

- Students will be able to define/describe/explain module, prefabrication, preassembly, offsite construction, modularization, PPMOF, and accelerated bridge construction (ABC).

- Students will be able to describe the key concepts and characteristics of modular construction;

- Students will be able to explain the key advantages, disadvantages, barriers, drivers, and enablers of modularization;

- Students will be able to discuss factors related to module transportation;

- Students will be able to apply the modularization business case process and the PPMOF tool, calculate a net present value for modular project, compare total installation costs between modularization and stick-built projects, and determine go/no-go for modularization;

- Students will be able to list execution plan differences for modularization;

- Students will be able to list modularization critical success factors for modularization

- Students will be able to describe standardization strategy for modularization;

- Students will be able to recognize the shipbuilding construction philosophy transformation and explain a path forward for construction.

- Students will be able to list ten enablers that will help to accelerate higher levels of modularization across the industry

\section{Required and recommended books and materials}

The course' textbook is Construction Industry Institute (CII; 2012). "Industrial Modularization: How to Optimize; How to Maximize." J. T. O'Connor, W. J. O'Brien, and J. O. Choi, eds., The University of Texas at Austin: Construction Industry Institute, Austin, TX. Required/recommended reference books and articles are: (Construction Industry Institute (CII) 2002, 2007, 2011; McGraw Hill Construction 2011; O'Connor et al. 2009). Other optional recommend readings are: (Choi 2014; Choi et al. 2016, 2017; Choi and O'Connor 2015; Gibb 1999; O’Brien et al. 2015; O’Connor et al. 2015b; c, 2017). 


\section{SPRING 2017COURSE EVALUATION RESULT}

Detailed result of Spring 2017 CEM/CEE 795 teaching/course evaluations (Table 1) is presented in this section to show the effectiveness of the course. Overall, the students who took the course in Spring 2017 were satisfied with the material, assignments, tests, and instructor's preparedness/knowledge/capability/fairness/performance.

Table 1. Detailed Result of Spring 2017 CEM/CEE 795 Teaching/Course Evaluations.

\begin{tabular}{|c|c|c|c|c|c|c|c|c|}
\hline & Total & $\begin{array}{c}\text { Excell } \\
\text { ent }\end{array}$ & Good & $\begin{array}{l}\text { Neutr } \\
\text { al }\end{array}$ & Fair & Poor & N/A & $\begin{array}{l}\text { Avera } \\
\text { ge }\end{array}$ \\
\hline $\begin{array}{l}\text { The material was } \\
\text { presented clearly... }\end{array}$ & 9 & 7 & 1 & 1 & 0 & 0 & 0 & 4.67 \\
\hline $\begin{array}{l}\text { The instructor was } \\
\text { genuinely interested in } \\
\text { educating the } \\
\text { students... }\end{array}$ & 9 & 8 & 1 & 0 & 0 & 0 & 0 & 4.89 \\
\hline $\begin{array}{l}\text { The assignments, } \\
\text { quizzes, and tests were } \\
\text { fair and covered the } \\
\text { material } \\
\text { emphasized... }\end{array}$ & 9 & 8 & 1 & 0 & 0 & 0 & 0 & 4.89 \\
\hline $\begin{array}{l}\text { The instructor was } \\
\text { well prepared in class } \\
\text { meetings... }\end{array}$ & 9 & 6 & 2 & 1 & 0 & 0 & 0 & 4.56 \\
\hline $\begin{array}{l}\text { The instructor was } \\
\text { available to answer } \\
\text { questions... }\end{array}$ & 9 & 7 & 2 & 0 & 0 & 0 & 0 & 4.78 \\
\hline $\begin{array}{l}\text { The instructor covered } \\
\text { the material listed in } \\
\text { the syllabus... }\end{array}$ & 9 & 8 & 1 & 0 & 0 & 0 & 0 & 4.89 \\
\hline $\begin{array}{l}\text { The instructor's } \\
\text { overall performance in } \\
\text { this course was... }\end{array}$ & 9 & 5 & 4 & 0 & 0 & 0 & 0 & 4.56 \\
\hline
\end{tabular}

Table 2. Summary of Spring 2017 CEM/CEE 795 Teaching/Course Evaluations Result.

\begin{tabular}{|c|c|}
\hline Course & CEM/CEE 795 \\
\hline Type & In Person \\
\hline Number of Enrolled & 10 \\
\hline Number of Evaluations & 9 \\
\hline Course Mean & 4.73 \\
\hline Graduate CEM* Instructors' Mean & 4.24 \\
\hline Graduate COE* Instructors' Mean & 4.55 \\
\hline Graduate CEM* Instructors' Median & 4.52 \\
\hline Graduate COE* Instructors' Median & 4.69 \\
\hline New Prep & Yes \\
\hline
\end{tabular}

$* \mathrm{CEM}=$ Construction Engineering and Management $\quad * \mathrm{COE}=$ College of Engineering 
The course evaluation result of the new course, CEE/CEM 795, outperformed CEE/CEM instructors' average: the course mean/CEE program mean/College of Engineering instructors' mean $=4.73 / 4.24 / 4.55$. Table 2 shows a summary of CEM/CEE 795 course evaluation result.

\section{Comments provided by the students about the course}

Positive comments:

- "Great topic, leading edge. This is a real class built to produce engineering graduates with real experience that can be directly used in their careers."

- "I'm hopeful that this can become 400/600 class (or a version of it at least) so that undergraduate students can share in the benefits..."

- "Very interesting course material, a bit redundant but very informative as well."

- “... a fantastic instructor, and the course content was good."

- "The assignments including report writing as well as presentation were very interesting."

- "I think the final synthesis report was the best part of the assignment which helped me understand the real research work."

Negative/constructive comments:

- "The instructor expects a lot out of his students which can be a bit overwhelming."

- "Felt like there was a lot of repetition for some things."

- "A lot of it felt like a thesis or dissertation defense."

- "Give some construction and contract terminology upfront at beginning of semester."

- "Maybe present concepts, business case analysis, PPMOF at first half of semester. The second half could be case studies of shipbuilding, industrial, institutional (prison, hospitals, schools, etc.), commercial, residential, then other applications."

- "maybe more examples of residential and commercial applications"

\section{CONCLUSION AND DISCUSSION}

The author developed a new graduate-level course on Modular Construction in 2017 which covers an overall understanding of modular construction concepts including, advantages, disadvantages, impediments, industry status, business case process, execution plans, critical success factors, and standardization strategies of modularization. Aligned with the author's long-term career goal, "to create an optimum environment for broader and more effective use of modularization," the author created the course to accelerate higher levels of modularization and meet the need of students and the industry based on the author's extensive research experience on modularization.

Overall, the students who took the course in Spring 2017 were satisfied with the course topics, material, assignments, tests, and instructor's preparedness/ knowledge/fairness/performance. Considering that the course was delivered for the first time as a graduate course, the author believes that it is fair to say that the course was well developed and delivered. There were two contradictory comments on the synthesis report. It seemed graduate students who have an interest in research enjoyed the synthesis report project; who do not have an interest in research felt a little bit overwhelming. Based on the constructive comments provided, the author plans to improve the course by 1) removing some of the repetitive material, 2) changing the order of delivering topics, 3 ) giving construction and contract terminology, terms, and jargons upfront at the beginning of 
semester, 4) and including more examples of residential and commercial applications, and 5) bringing more modular experts to the classroom as a guest lecturer.

In addition to the course improve efforts, the author plans to advance the course further in the near future in two ways. First, the course syllabus, topics and high level contents will be presented during the CII Modularization Community of Practice (MCOP)'s face-to-face meeting. The members of CII MCOP are the subject matter experts on modularization who shares the knowledge of modularization in plan, design, and execution of capital facility projects. The author plan to get feedback from the MCOP members to gain opinion from the practitioners' view. Second, currently, in 2017/2018, the author and CII COP are supporting CII's Online Education team with a development of Modularization Online Education modules for CII member practitioners. The author plans to continue collaborating with modular practitioners and obtain more real modularization problems, and challenge students with the problems.

Modular Construction is a dynamic and fascinating subject to learn and teach. Since the author's first year as a graduate student, the author has been attracted to modularization, taking numerous courses and seminars related to modularization. The author believes an instructor's passion for modularization will have a positive impact on the relationships an instructor form with students, in addition to the impact it will have on how an instructor convey knowledge to students. The author hopes that 1 ) the students who take this course become a leader changing a paradigm and promoting a new design process with modularization when they become owners, designer, and contractors; 2) the course accelerate higher levels of modularization and meet the need of students and the industry; and 3) more engineering schools establish and promote a modular approach.

\section{ACKNOWLEDGEMENTS}

The author would like to thank Construction Industry Institute at the University of Texas at Austin for allowing the author to reproduce and distribute the CII products in the classroom for graduate students at UNLV.

\section{REFERENCES}

Choi, J. O. (2014). "Links between Modularization Critical Success Factors and Project Performance." Ph.D. Dissertation, The University of Texas at Austin, Austin, TX.

Choi, J. O., Chen, X. B., and Kim, T. W. (2017). "Opportunities and challenges of modular methods in dense urban environment." International Journal of Construction Management.

Choi, J. O., and O'Connor, J. T. (2015). "MODULARIZATION BUSINESS CASE ANALYSIS: LEARNING FROM INDUSTRY PRACTICES TOOL." 2015 Modular and Offsite Construction (MOC) Summit \& 1st International Conference on the Industrialization of Construction (ICIC), M. Al-Hussein, O. Moselhi, S. Kim, and R. E. Smith, eds., University of Alberta, Dept. of Civil \& Environmental Engineering, Edmonton, Alberta, Canada, 69-76.

Choi, J. O., O'Connor, J. T., Kim, T. W., O'Connor, J. T., and Kim, T. W. (2016). "Recipes for Cost and Schedule Successes in Industrial Modular Projects: Qualitative Comparative Analysis." Journal of Construction Engineering and Management, 142(10), 4016055.

Construction Industry Institute (CII). (2002). Implementing the Prefabrication, Preassembly, Modularization, and Offsite Fabrication Decision Framework: Guide and Tool. The University of Texas at Austin: Construction Industry Institute, Austin, TX. 
Construction Industry Institute (CII). (2007). Examination of the shipbuilding industry. The University of Texas at Austin: Construction Industry Institute, Austin, TX.

Construction Industry Institute (CII). (2011). Transforming Modular Construction for the Competitive Advantage through the Adaptation of Shipbuilding Production Processes to Construction. The University of Texas at Austin: Construction Industry Institute, Austin, TX.

Construction Industry Institute (CII). (2012). Industrial Modularization: How to Optimize; How to Maximize. The University of Texas at Austin: Construction Industry Institute, Austin, TX.

Gibb, A. G. F. (1999). Off-site fabrication: prefabrication, pre-assembly and modularisation. J. Wiley, New York.

McGraw Hill Construction. (2011). Prefabrication and Modularization: increasing productivity in the construction industry. SmartMarket Report.

O'Brien, W. J., O'Connor, J. T., and Choi, J. O. (2015). "MODULARIZATION BUSINESS CASE: PROCESS FLOWCHART AND MAJOR CONSIDERATIONS." 2015 Modular and Offsite Construction (MOC) Summit \& 1st International Conference on the Industrialization of Construction (ICIC), M. Al-Hussein, O. Moselhi, S. Kim, and R. E. Smith, eds., University of Alberta, Dept. of Civil \& Environmental Engineering, Edmonton, Alberta, Canada, 60-67.

O'Connor, J. T., Damiano, V. P., Kulkarni, R., and Clark, P. (2009). "Executing a standard plant design using the 4X model." Hydrocarbon Processing, 88(12), 47-53.

O'Connor, J. T., O’Brien, W. J., and Choi, J. O. (2015a). "Standardization Strategy for Modular Industrial Plants." Journal of Construction Engineering and Management, 141(9), 4015026.

O'Connor, J. T., O'Brien, W. J., and Choi, J. O. (2015b). "Industrial Project Execution Planning: Modularization versus Stick-Built." Practice Periodical on Structural Design and Construction, 12.

O'Connor, J. T., O'Brien, W. J., and Choi, J. O. (2015c). "Standardization strategy for modular industrial plants." Journal of Construction Engineering and Management, 141(9).

O'Connor, J. T., O'Brien, W. J., and Choi, J. O. (2017). "INDUSTRY-WIDE MAXIMIZATION ENABLERS FOR HIGHER LEVELS OF MODULARIZATION." The First International Conference on Maintenance and Rehabilitation of Constructed Infrastructure Facilities (MAIREINFRA1), Hosin "David" Lee, ed., international Society for Maintenance And Rehabilitation of Transport infrastructures, Seoul, S. Korea, 1-6. 